\title{
ARIIGO
}

\section{Do patrimônio cultural e seus significados}

\author{
On cultural heritage and its meanings
}

Fátima Maria Alencar ARARIPE ${ }^{1}$

R E S U M O

Reflexões acerca do patrimônio cultural tendo em mente o conjunto de tudo o que encontramos na formação da cultura: conhecimento, crenças, arte, moral, direitos, costumes, capacidade e hábitos adquiridos pelo homem, transmitidos de geração a geração e a dimensão da força simbólica do seu significado, como representação da expressão cultural do fazer social. Propõe (re)definir o patrimônio cultural, como memória social e, por conseguinte, parte da história, na possibilidade de pensar esse patrimônio parte de um grande acervo informacional, isto é, como fonte de informação, inserido nos processos de ensino e de pesquisa, de forma a possibilitar a construção de um ser socialmente ativo. Este ser, ao unir passado e presente, (re)cria imagens da cidade - espaço por excelência da formação do patrimônio, do povo e da cultura, observando as condições históricas, sociais e comunicacionais, bem como as exigências contemporâneas, que levam em consideração a produção humana como bem cultural e, portanto, da maior significação. Este ensaio apresenta o patrimônio cultural desde a perspectiva dos usos sociais, das apropriações que a sociedade faz da sua memória, da sua história, para que haja reconhecimento e legitimação desse patrimônio que, conseqüentemente, será elemento a permear o processo educacional e formação da cidadania.

Palavras-chave: patrimônio cultural, memória social, cidade, fonte de informação.

\footnotetext{
${ }^{1}$ Docente, Departamento de Ciência da Informação, Universidade Federal do Ceará. Av. Universidade, 2768, Benfica, 60020180, Fortaleza, CE, Brasil. E-mail: fararipelufc.br

Recebido em 8/7/2003 e aceito para publicação em 17/8/2004.
} 
A B S T R A C T

The author reflects upon the cultural heritage, considering everything that contribute to the culture formation knowledge, beliefs, art, morals, rights, customs, capacities and habits acquired by the human being and transmitted from generation to generation, and the dimension of the symbolic forces of their meaning, as representation of the cultural expression of social making. The author intends to (re)define cultural heritage as social memory and, therefore, part of the history, arguing that this will make it possible to approach such heritage as part of a great information collection: as a source of information, within the educational and research processes, aiming at the construction of a socially active being, who, joining past and present, would (re)create images of the city - par excellence, the formation space of heritage, as well as images of the people and the culture, observing the historical, social and communication conditions. Such socially active being would accomplish all that, by taking into account, also, the contemporary requirements, which consider human production as a cultural good, therefore, one of the utmost significance. The author intends to approach the cultural heritage from the perspective of the social uses, the appropriation of its own history by society, which, thus, recognizing and legitimating such heritage, consequently turning its elements into facilitators of the educational and citizenship processes.

Key words: cultural heritage, social memory, city, information source.

\section{[...]}

Que tristeza que nós sentia.

Cada tauba que caía

Doía no coração.

[...]

Adoniran Barbosa

As escolas de Biblioteconomia trazem no seu currículo disciplinas de cunho histórico e social, bem como o estudo das fontes de informação - nos seus mais variados suportes documentais. Todavia, não podemos afirmar que faz parte desse acervo os elementos que permeiam o fazer social e se representam naquilo que denominamos patrimônio cultural e podem contribuir para a construção de uma sociedade que se (re)conheça naquilo que apresenta e representa como parte da sua cultura. Portanto, se exige uma revisão da base que rege o patrimônio, haja vista o aspecto simbólico nele implícito. Este texto pretende desenvolver algumas reflexões sobre patrimônio cultural, memória e cidade, como possibilidade de repensar o ensino e a pesquisa no que se refere àquilo que denominamos fontes de informação e a necessidade, que acreditamos seja possível e necessária, da inserção desse aparato cultural ou informacional, no conteúdo programático das disciplinas que trabalham com história e sociedade brasileiras.

Consideramos da maior riqueza o que se apresenta no patrimônio cultural, como memória social, no espaço da cidade, e sua utilização 
como fonte de (in)formação e, conseqüentemente, coadjuvante na promoção de tudo o que possibilita ao sujeito um crescimento pessoal e coletivo para a construção da sociedade.

$\mathrm{Na}$ interseção de reflexões acadêmicas e experiências pessoais, não pretendemos neste momento aprofundar as reflexões teóricas, nem tampouco proferir um receituário de procedimentos que viabilizem diminuir a distância do uso desse aparato na prática docente. Pretendemos, sim, alertar para a necessidade de pensar o ensino através de novas ferramentas de aprendizagem, de sair dos equipamentos tradicionais e navegar em outros textos, observando em cada um deles as diferentes dimensões da existência humana: política, econômica, religiosa, dentre outras.

No Brasil, quando se criou o Serviço de Patrimônio Histórico e Artístico Nacional (SPHAN), em 1937, as discussões sobre o campo patrimonial foi ocupada por arquitetos e alguns poucos teóricos da cultura. Isto é, os bens patrimoniais instituídos eram designados com o olhar voltado para um patrimônio edificado: para prédios e monumentos visíveis e de certa forma estáticos. No entanto, é mister que se veja o patrimônio como parte integrante da comunidade onde está inserido, numa representação das manifestações sociais que marcam ou marcaram suas vidas, conquistas, sonhos, realizações e que constroem a história, e a possibilidade de olhar esse patrimônio como memória social.

Sem perder de vista a relevância da esfera edificada, é preciso incluir no patrimônio cultural outros campos artísticos e objetos do cotidiano - pintura, música, escultura, cinema, vestimentas, utensílios domésticos, instrumentos de trabalho, dentre outros, bem como materiais de diferentes arquivos e acervos.

Diante desse conjunto de bens patrimoniais vemos, no último quartel do século vinte, emergirem discussões que falam de um patrimônio material e imaterial. Essa é uma discussão da qual ainda não podemos compartilhar, na medida em que consideramos que um contém o outro, isto é, um se firma na relação com o outro e é a materialização do outro. Enfim, quando falamos de patrimônio cultural estamos nos referindo ao conjunto de tudo que tem significação, aquilo que tem sentido social, não importando se esse patrimônio é algo materializado (visível) ou simplesmente manifestações da cultura que se apresentam através do cidadão comum.

Se levarmos em consideração essas duas dimensões ou essas duas possibilidades de classificar o patrimônio, é preciso que estejamos atentos para além de um patrimônio "material" que é também estático, e pensarmos em um patrimônio "imaterial", que é dinâmico, que pode caminhar, um patrimônio que tem leveza e movimento. Não podemos esquecer que vivemos em um mundo marcado pela tecnologia, e que nesse mundo tecnológico o patrimônio tem a possibilidade de estar, também, no virtual, numa dinâmica que Ihe dá presença na ausência, desenraizado e com uma mobilidade característica da contemporaneidade.

Essa ampliação do que contempla o patrimônio cultural não diz respeito apenas a diversidade de objetos, ou novos objetos e temas, mas sim, que estamos diante de uma dimensão maior, da dimensão humana de fazeres sociais, isto é, das práticas cotidianas. A epígrafe citada no início deste texto, o pequeno trecho da música de Adoniran Barbosa, "Saudosa Maloca", simbolicamente vem nos mostrar o quanto é importante olhar as experiências sociais que acompanham os objetos, os lugares, as músicas, pois dizem respeito a inúmeras trajetórias de vidas em diferentes momentos - são memórias, em nuances que vão do político e do religioso ao social, por meio dos diferentes segmentos sociais, englobando o homem comum e, portanto, não supondo que o patrimônio tenha significado igual para todos.

Como afirma Silva: "É procurar profundas raízes ou tenras e novas folhas daquilo que os 
seres humanos andaram (e continuam) fazendo. É interpretar pacientemente o social [...]" (SILVA, 1995, p.24).

Pensando assim, algumas questões emergem, são inquietantes e pedem respostas: patrimônio cultural e memória de quem? O que representa socialmente? É uma memória que se diz coletiva ou instituída pela instância governamental ou empresarial? O que é patrimônio cultural? Passado ou presente?

Costumamos pensar que o patrimônio é passado, memória daquilo que ficou como herança. Mas o patrimônio, também, é presente, é memória do tempo presente. Isso porque não podemos entender o presente, nem tampouco pensar o futuro, sem olhar para a memória - pano de fundo para se pensar as mudanças sociais. Em se tratando de passado temos um patrimônio que agrupa pessoas e acontecimentos que testemunham períodos vividos. São memórias que profissionais e instituições credenciam como patrimônio: preservando-os, recuperando-os e conservando-os.

Primeiramente apontamos a preservação, através de um registro oficial e/ou social que os resguarde do esquecimento ou de possíveis danos, pois é mister que ao pensar em preservação não nos fixemos nos feitos históricos. É necessário lembrar que existe um patrimônio que se encontra nas práticas cotidianas e é preciso que também seja preservado, isto é; apresentado como tal e com valor social.

Em segundo lugar, e na mesma importância, recuperando-os, tanto em suas estruturas físicas como nas realizações do homem em seu fazer cotidiano, quer seja nos festejos religiosos, nos costumes folclóricos, nos ritos de passagem, nas manifestações políticas, dentre outros.

E em terceiro, conservando-os, na perspectiva de manter a memória como fonte para a reflexão histórica e a construção do espaço urbano, bem como na possibilidade e necessidade de uso social desse patrimônio, numa relação mais próxima com o processo educacional, já que acreditamos que o patrimônio é pedagógico. Se não dermos uma utilidade social ao que julgamos ou que se apresenta como patrimônio, ele com certeza morre ou, no mínimo, passa desapercebido.

Há, também, na memória contida no patrimônio um veio para se obter uma identidade e os laços de pertencimento com a comunidade onde se insere. Com todas as implicações que acompanham as discussões sobre identidade cultural no presente momento, ainda assim acreditamos dever existir uma relação de reconhecimento e pertencimento - de identidade, daquilo que se constitui como patrimônio com a história do seu povo e as suas práticas cotidianas.

No que diz respeito à contemporaneidade o patrimônio agrupa pessoas, acontecimentos e coisas de quem fala e ouve, assim como se encontra presente nos projetos diferenciados e alternativos na sociedade, nas múltiplas identidades das classes sociais, nos grupos de idade, nas etnias, gêneros, correntes partidárias, etc. É passado e presente se conjugando na formação de um patrimônio memória representativo do fazer social.

Pensar na formação de um profissional que tem na informação a sua matéria prima e, ainda, numa multiplicidade de fontes de (in)formação, pressupõe a possibilidade da incorporação desse aparato informacional no seu universo profissional e, portanto, a necessidade de trazer essa problemática para o ensino e a pesquisa, como forma de viabilizar a legitimação dos valores patrimoniais existentes.

Queremos na verdade afirmar que a área biblioteconômica precisa ampliar o raio das conhecidas e tradicionais fontes de informação, desse conceito linear que olha apenas para aquilo que conseguimos juntar ou agrupar de forma ordenada e organizada. Há que se pensar em um acervo informacional que se encontra em 
qualquer lugar, de diferentes formas e sem nenhum ordenamento planejado, mas que diz muito da cultura e da história das pessoas e dos lugares. É um acervo dinâmico, pois é construído pelo movimento da vida.

Acreditamos, dessa forma, seja necessário um olhar mais acurado para as questões culturais, haja vista que os estudos antropológicos acerca de cultura apresentam uma variedade de conceitos que abrangem desde o modo de pensar, o modo de viver, e ao comportamento do homem, englobando um conjunto formado pelo conhecimento, crenças, arte, moral, direito, costumes, capacidade e hábitos adquiridos pelo homem como ser social, e a sua transmissão de geração a geração pelo processo da aprendizagem, compondo a paisagem social.

O patrimônio, pelo seu teor simbólico e sua significação, funciona como chave de entrada para a compreensão de uma época, de uma sociedade, ou de um momento da vida social. É que quanto mais mergulhamos nos movimentos do passado e nos debruçamos sobre os fatos particulares da vida cotidiana, mais podemos desvendar e compreender a estrutura e a regularidade desse passado e verificar que em um mesmo contexto estão reunidos diferentes fatos que, na verdade, formam a unidade social. É que a dinâmica do entrelaçamento social está na junção desses fatos, que se integram e formam unidades cada vez maiores, conduzindo as mudanças sociais, e, dessa forma, mostram que está na interdependência dos homens e das instituições a configuração global da sociedade.

As nossas reflexões direcionam o olhar para o espaço urbano da cidade, na perspectiva do que nela podemos encontrar de memória e de história dos seus moradores e, por conseguinte, como representação social. Tornou-se, na verdade, uma paixão olhar o que faz uma cidade, isto é, o que dá o movimento da vida, através da sua gente, de suas memórias e constróem a sua história.

\section{Barthes (1987) afirma que:}

A cidade é um discurso, e esse discurso é verdadeiramente uma linguagem: a cidade fala aos seus habitantes, nós falamos a nossa cidade, a cidade onde nós nos encontramos simplesmente quando a habitamos, a percorremos, a olhamos.

Porque da cidade emana uma polifonia ${ }^{2}$ discursiva de grandes dimensões. É necessário, portanto, que ao olhar a cidade se perceba que esse é um espaço de construção do homem e, portanto, cada pedra, cada parede levantada, cada instituição criada, assim como a forma com que se apresentam, ocupam lugar na organização da cidade e determinam a sua função, construindo inúmeros significados. Dessa forma, ainda seguindo o pensamento de Barthes (1987, p.189), devemos admitir que

Qualquer cidade é um pouco construída, feita por nós à imagem do navio Argos, em que cada peça já não era uma peça de origem, mas continuava a ser sempre o navio Argos, isto é, um conjunto de significações facilmente legíveis e identificáveis. Neste esforço de semântica da cidade, devemos tentar compreender o jogo dos signos, compreender que qualquer cidade é uma estrutura [...].

É a cidade deixando de ser apenas um conceito geográfico para tornar-se um símbolo irrefutável da existência do homem, onde é possível descobrir o que ela contém e o que ela esconde. A cidade é, portanto, lugar de memória, que abrange desde o seu traçado até a sua nomenclatura, bem como todos os textos

\footnotetext{
2 Polifonia: conceito da autoria de Bakthin, elaborado a partir dos estudos que esse autor fez nas dbras de Rabelais (romance) . Diz respeito às diferentes vozes que entram na composição dos textos de qualquer espécie, mas, neste caso, nos textos culturais, nas vozes que se expressam nos palcos, espaços e textos da cidade. Estas vozes disputam sentidos, entre si, e propõem sentido para os sujeitos.
} 
escritos sobre ela: são as obras arquitetônicas e urbanísticas, assim como tudo o que fala da sua cultura, da literatura, das artes plásticas, da música, e tantos outros aspectos que revelem uma cidade.

Portanto, procurar no espaço da cidade a visibilidade da sua história é buscar a memória, e a memória encontra-se nessa paisagem, conjunto de tudo que descortina pessoas, instituições, arte, literatura e que possa falar e construir a história desta cidade. Por conseguinte, observamos a cidade, o lugar de produção de sentidos, com um olhar plural e verificando que o seu verdadeiro significado encontra-se na relação homem/lugar.

Quando Rossi (1995, p.1) nos diz que "A arquitetura é a cena fixa das vicissitudes do homem, carregada de sentimentos de gerações, de acontecimentos públicos, de tragédias, de fatos novos e antigos", está nos dizendo que a cidade é um texto com vozes que falam dos sinais da vida cotidiana, das necessidades e dos sonhos de cada um dos indivíduos e do conjunto de todos eles. Essas vozes, que falam da cidade, é que, aos poucos, vão construindo a sua memória, uma memória que é social.

Parece-nos que a cidade oferece um acervo cultural - uma memória - que pode representar um importante papel de construção social que minimize as desigualdades e diferenças apreendidas na escola e, assim, contribuir para uma educação transformadora. Observamos, por conseguinte, que o conhecimento e o reconhecimento do que "esconde" a cidade é por demais significativo como fonte de (in)formação no processo educacional e a construção de um "indivíduo cidadão".

Olhar o espaço da cidade tem merecido, da nossa parte, uma atenção especial. Ao caminharmos por diferentes lugares, e aqui elegemos o estado do Ceará, mais especificamente a cidade de Fortaleza, uma inquietação nos acompanha, proveniente de observações e reflexões cotidianas quanto ao que se apresenta e representa como patrimônio e, portanto, como memória social, e que parece não fazer parte do olhar e do reconhecimento social. São reflexões que ultrapassam o limite do visível para pensar e entender um patrimônio que se encontra, também, no cotidiano do "homem ordinário", como diz Michel de Certeau (1994), e que, com certeza, são de extrema relevância para o ensino e a pesquisa.

São praças, monumentos, prédios e ruas que contam a história da cidade de Fortaleza, que se encontram sem preservação, sem recuperação e sem conservação. A apropriação que deles se faz é das mais variadas: são pichados, depredados, utilizados para moradia ou para esconderijo, sem nenhum sentimento de reconhecimento do que aquilo representa na história da construção dessa cidade.

Ainda nas mesmas proporções podemos ver o pouco valor atribuído aos cânticos e danças características da região, bem como ao seu rico artesanato, dentre outros encantos que podem mostrar a feição e a identidade da cidade.

Esses comportamentos que destroem os espaços, os objetos e anulam as manifestações culturais são provenientes, muitas das vezes, das injustiças sociais. Mas, por outra, podem denotar desconhecimento, indiferença ou sentimento de posse, oriundos da inexistência de uma educação que contemple o espaço de vida cotidiana, uma educação patrimonial.

São grandes questões que envolvem o patrimônio cultural e dão significado a sua existência e nos inquietam: de quem, para quem, para o que servem, dentre outras indagações, e que ainda não podemos dar respostas, pois são o motivo da pesquisa em andamento para a nossa tese de doutoramento.

Dessas considerações surgiram muitos questionamentos frente à necessidade de se mostrar um patrimônio cultural, que é memória e, por conseguinte, é história, que apresente os laços de pertencimento de uma sociedade, numa 
retomada de valores que possa garantir alcançar a construção de um futuro alicerçado numa educação que busque o passado e detenha o seu olhar no presente, nesse presente de uma sociedade caracterizada pela chamada modernidade, e notadamente marcada pela tecnologia e pela globalização.

Pensar a questão do patrimônio cultural olhando esse conjunto, observando a dimensão da força simbólica do seu significado, e a sua representação enquanto expressão cultural do fazer social, marcada pelos fatos, contextos, interpretações, significações e sentidos dessas práticas é, no mínimo, interessante.

Portanto, (re)definir o patrimônio cultural, como memória social e, por conseguinte, como fonte de (in)formação, levando em consideração as condições históricas, sociais e comunicacionais na contemporaneidade, que exalta a produção humana como bem cultural da maior significação para a construção de um ser socialmente ativo, unindo passado e presente e (re)criando imagens da cidade, do povo, da cultura, é fundamental para que se possa ter perspectivas de falar de uma educação cidadã que reconheça as diferenças culturais do indivíduo e suas necessidades informacionais.

É pelo patrimônio, como memória social, que podem se projetar as significações que delinearão e formarão as representações sociais. É o patrimônio, enquanto fonte de (in)formação, como testemunha das mudanças e não da permanência das sociedades, se apresentando de forma dinâmica e ao qual se atribuem valores, não só materiais mas, principalmente, culturais, com uma valiosa carga de representação simbólica. É o patrimônio cultural pensado na perspectiva dos usos sociais e das apropriações que a sociedade faz da sua memória, da sua história.

É verdade que todos esses aspectos permeiam o que denominamos cultura, mas não podemos deixar de observar que tudo isso se constitui através da racionalidade e da sensibi- lidade do ser humano ao utilizar a sua capacidade imaginativa na construção do social. Construção essa que se dá na e pela experiência vivenciada e que essencialmente não se realiza sem ela, haja vista a necessidade do conhecimento e do reconhecimento dos equipamentos sociais para a compreensão daquilo que se instaura como cultura, observando os aspectos espaço (construção da memória) e o tempo, enquanto tempo universal que os homens partilham.

Portanto, pensar "[...] o modo como em diferentes lugares e momentos uma determinada realidade social é construída, pensada, dada a ler"(CHARTIER, 1988, p.16); é observar a capacidade imaginativa do homem como possibilitadora da construção do social, mediante uma diversidade de significados relacionados a momentos e épocas vividos. Dessa forma, podemos trabalhar a cultura tomando como base as práticas e representações sociais, observando

[...] uma história cultural do social que tome por objeto a compreensão das formas e dos motivos - ou por outras palavras, das representações do mundo social - que à revelia dos atores sociais, traduzem as suas posições e interesses objetivamente confrontados e que, paralelamente, descrevem a sociedade tal como pensam que ela é, ou como gostariam que fosse (CHARTIER, 1988 p.19)

A cultura, dessa forma, aqui é apresentada como resultante das práticas sociais que, através das ações dos homens, tem uma representação enquanto expressão cultural no seio da sociedade. Observamos, portanto, que os homens não passeiam desnudos na construção do social. Eles, homens, precisam de signos, de imagens, de gestos, dentre outros aspectos, carregados de sentido, através dos quais possam se comunicar e ainda se reconhecerem a si próprios no seu caminhar como ser social e, por conseguinte, como ser eminentemente simbólico. 
Há uma força social que congrega e une os homens quando elaboram uma determinada representação de si; quando estabelecem papéis e posições sociais; quando exprimem e impõem crenças comuns e constróem uma memória.

É que esses homens vivem em meio a um grande acúmulo de mecanismos passados e, nada mais natural, do que buscar nesses mecanismos aquilo que melhor se adeqüe aos seus próprios fins. Quando pensamos a memória como social não podemos esquecer que o homem é um ser único, singular, e, portanto, com identidade própria, sentimentos e uma compreensão própria de tudo que o rodeia.

Entretanto, é necessário observar, também, que esse mesmo homem faz parte de um determinado grupo e, dessa maneira, existe um sentimento de pertencimento desse homem com o tempo e o lugar, e as pessoas que formam esse grupo, fazendo com que adquiram significados coletivos.

Geertz (1978, p.15) acredita

[...] que o homem é um animal amarrado a teias de significados que ele mesmo teceu, [...] [e] a cultura como sendo essas teias e a sua análise; portanto, não como uma ciência experimental em busca de leis, mas como uma ciência interpretativa, a procura de significados.

Assim, podemos então afirmar que o comportamento do homem pode ser visto como uma ação simbólica que somente pode se constituir pela e na interpretação, possibilitada pelo contexto, através do procedimento essencial do situar-se, que permite uma compreensão mais próxima da realidade dos fatos. Portanto,

Olhar as dimensões simbólicas da ação social - arte, religião, ideologia, ciência, lei, moralidade, senso comum - não é afastar-se dos dilemas existênciais da vida [...] é mergulhar no meio delas. A vocação essencial da antropologia interpretativa não é esconder as nossas questões mais profundas, mas colocar à nossa disposição outros carneiros em outros vales - e assim incluí-las no registro de consultas sobre o que o homem falou (GEERTZ, 1978, p.40).

Em meio a essa teia simbólica os homens, enquanto cidadãos do mundo, com suas memórias, tornam-se fonte de legitimação da representação do passado e da história do tempo presente, já que existe uma coerência e uma relação entre passado e presente que podem ser percebidas nas práticas cotidianas.

Refletir sobre o patrimônio cultural, como expressão da cultura do homem, olhando a dimensão simbólica, a força do poder simbólico, nos fatos e ações que se fazem presentes na construção do social tem importância significativa, na medida em que envolve a memória como recurso de reconstrução histórica, e a identidade, com toda a complexidade que o conceito envolve - como forma de legitimação e reconhecimento do que se apresenta como patrimônio, possibilitando ao homem se encontrar, se identificar e acreditar que o que ele vê faz parte da sua memória, da memória do seu grupo.

A questão que propomos é (re)definir o patrimônio cultural, levando em consideração as condições históricas, sociais e comunicacionais da contemporaneidade, mas um patrimônio que é memória do seu povo, e que pode ser utilizado como fonte de (in)formação para a pesquisa e o ensino.

Existe uma preocupação advinda de instituições, sejam públicas ou privadas, de organizações governamentais e não governamentais, grupos sociais e algumas poucas figuras públicas, no que diz respeito ao patrimônio cultural, através da criação e/ou manutenção de museus, memoriais, centros de documentação e de memória, dentre outros. Percebemos, no entanto, a partir de leituras e 
do nosso conhecimento empírico sobre essa questão, a necessidade de uma pesquisa científica, o que estamos a realizar durante o doutorado, que realce o uso dos bens patrimoniais como fonte de (in)formação para o ensino e a pesquisa com vistas à formação de "indivíduos cidadãos".

Essa, no entanto, não tem sido uma preocupação apresentada. Parece-nos que o patrimônio ficou entregue nas mãos dos profissionais da área arquitetônica que privilegiam, por conseguinte, as edificações, ou melhor expressando o patrimônio edificado. De acordo com a primeira legislação patrimonial do país, o Decreto-lei no 25/37 diz que:

Constitui o patrimônio histórico e artístico nacional o conjunto de bens móveis e imóveis existentes no país e cuja conservação seja de interesse público, quer por sua vinculação a fatos memoráveis da História do Brasil, quer por seu excepcional valor arqueológico ou etnográfico, bibliográfico ou artístico (BRASIL, 1937).

A política que norteou a preservação dos bens patrimoniais, sob o comando do SPHAN, desde o ano de sua criação, privilegiou, como salienta Oriá (1997, p.131), "[...] igrejas barrocas, os fortes militares, as casas-grandes e os sobrados coloniais." Esqueceram "as senzalas, os quilombos, as vilas operárias e os cortiços."

A idéia era passar ao país a imagem de um passado uno, homogêneo, onde não se reservava espaço para as diferenças étnicas e culturais da formação histórica nacional. Ficou, dessa forma, o patrimônio como um dos campos instituidores da memória, num viés particular de atuação do poder público, deixando de lado a participação da sociedade na legitimação desses bens.

As exigências contemporâneas fizeram com que se ampliasse a designação "patrimônio histórico e artístico" para "patrimônio cultural", levando-se em consideração toda a produção humana como bem cultural.

A atual Constituição Brasileira vem reforçar essa tendência quando adota, no artigo 216, Seção II - Da Cultura, para patrimônio cultural a seguinte conceituação:

Constituem patrimônio cultural brasileiro os bens de natureza material e imaterial, tomados individualmente ou em conjunto, portadores de referência à identidade, à ação, à memória dos diferentes grupos formadores da sociedade brasileira, nos quais se incluem:

I - as formas de expressão;

II - os modos de criar, fazer e viver;

III - as criações científicas, artísticas e tecnológicas;

IV - as obras, objetos, documentos, edificações e demais espaços destinados às manifestações artísticoculturais;

$\mathrm{V}$ - os conjuntos urbanos e sítios de valor histórico, paisagístico, artístico, arqueológico, ecológico e científico (BRASIL, 1988).

É o patrimônio agora tomado como importante elemento na construção de uma identidade nacional. É o passado como referência para a constituição da nacionalidade e fonte de conhecimento para a história. Podemos, então, olhar o patrimônio como suporte de evocação e de memória. Como fenômeno social que une passado e presente (re)criando imagens da cidade, do povo, da cultura. Devemos, portanto, olhar o patrimônio, enquanto memória social, como lugar onde se projetam as significações que delinearão e formarão as representações sociais e tem na cidade seu lugar privilegiado.

De acordo com Canclini (1994, p.95) as ciências sociais estão reconceitualizando patrimônio cultural tomando alguns pontos como fundamentais. 
Primeiramente a afirmação de que o patrimônio não se restringe mais somente às expressões "mortas" da cultura - situando-se nesse meio antigos objetos, sítios arqueológicos etc. - mas, também, a outras formas de bens culturais - visíveis e invisíveis - como língua, conhecimento, documentação, comunicação, dentre outros.

Em segundo, a questão das apropriações e dos usos sociais que se fazem desse patrimônio frente às necessidades contemporâneas e a exigência de uma política de preservação e administração desses bens patrimoniais, que possa fazer valer a existência dos mesmos.

E em terceiro, o reconhecimento de um patrimônio que se faz presente nos produtos da cultura popular - música, textos de camponeses e operários, bens materiais e simbólicos, originários de todos os grupos sociais.

Destaca então o autor, seis questões teóricas e políticas a serem trabalhadas:

1) o patrimônio cultural e a desigualdade social; 2) a construção imaginária do patrimônio nacional; 3) os usos do patrimônio; 4) os propósitos da preservação; 5) o patrimônio na era da indústria cultural; 6) os critérios estéticos e filosóficos [que o avaliam, preservam e difundem] (CANCLINI, 1994, p.96)

Sem descartar a relevância do conjunto das seis questões levantadas, gostaríamos aqui de destacar três aspectos que consideramos da maior importância: a construção imaginária do patrimônio cultural; os usos do patrimônio; e os propósitos da preservação, observando que esses três aspectos estão imbricados de uma maneira tal que falar em um deles requer uma relação com os outros dois, sem perder de vista a paisagem contemporânea que mostra, a todo momento, uma quebra de fronteiras, uma desterritorialização, ou ainda uma invasão dos nossos espaços com uma enxurrada de novas maneiras de dizer, de fazer e de pensar, isto é, com novas formas de sociabilidade.

É interessante, portanto, além de pensar numa memória que mantenha conexão com os bens patrimoniais - tais como monumentos e fatos históricos, que se considere o indivíduo como um cidadão e, por conseguinte, merecedor de memória - individual e coletiva - que lhe permita uma consciência histórica capaz de possibilitar a esse cidadão o (re)conhecimento desses bens como parte da sua memória e da sua história.

O patrimônio cultural precisa ser pensado não só nos princípios políticos que norteiam as estruturas jurídicas e sociais, mas pautado, especialmente, numa cultura formada pelas ações e invenções do cotidiano.

[...] é preciso interessar-se não pelos produtos culturais oferecidos no mercado de bens, mas pelas operações dos seus usuários; é mister ocuparse com 'as maneiras diferentes, demarcar socialmente o desvio operado num dado por uma prática (CERTEAU, 1994, p.13).

Nesta perspectiva nos deparamos com o segundo aspecto aqui destacado: os usos do patrimônio. As contradições no uso do patrimônio - como espaço de disputa política, econômica e simbólica - ficam a cargo do setor privado, do Estado e dos movimentos sociais. A iniciativa privada trata o patrimônio enquanto instância possibilitadora de ganhos econômicos, ficando o aspecto cultural, na maioria das vezes, à margem dos interesses empresariais: em especial o setor imobiliário e o setor turístico. $\mathrm{O}$ Estado, ao mesmo tempo em que valoriza o patrimônio como elemento integrador de nacionalidade, por outra vem se utilizando apenas dos fatos e ações históricas que se ligam aos bens patrimoniais para construir um imaginário social.

Não podemos esquecer que nesse caminho a ação do Estado tem, também, além 
de identificar, reabilitado bens patrimoniais de grande valor artístico e cultural. Mas, por outra, esquecendo-se de identificar em outros fatos e ações, provenientes das práticas sociais - como diz Chartier - uma representação da memória que contemple o cidadão do mundo, o cidadão comum.

Os movimentos sociais em torno do patrimônio despontam com preocupações que vão desde as questões ecológicas, a urbanização descontrolada, com vistas a preservação de um ambiente urbano em condições saudáveis de vida, além de trabalharem na construção de centros de memória que possibilitem um registro de suas identidades culturais.

Temos então aqui, o terceiro aspecto destacado. E uma interrogação emerge: por que preservar o patrimônio?

Difícil se torna para uma sociedade a constituição e, principalmente, a preservação dos bens patrimoniais, se essa sociedade não consegue se ver nos ícones, nos símbolos e monumentos instituídos por concepções que envolvem, em maiores proporções, questões econômicas e políticas. É preciso que se preserve um bem cultural não só pelo valor estético, arquitetônico ou histórico, mas sim se esse bem tem significação para a comunidade onde está inserido, possibilitando uma melhoria na qualidade de vida de seus moradores e contribua para a construção e o exercício da cidadania.

Faz-se necessário que os bens patrimoniais sejam identificados através das coisas que falem das memórias do seu povo, do seu viver. Nessa perspectiva, temos que pensar num patrimônio que se faz na memória - individual e coletiva - que possa representar o passado, a tradição e a história de um país, estado, cidade ou comunidade. É na memória acumulada que os indivíduos se reconhecem enquanto ser social e sujeitos partícipes na construção de uma identidade local, que apresente passado e presente numa sucessão de interligações. Sem memória é impossível ao homem situar-se no tempo da história e, portanto, sentir-se sujeito dessa história.

Precisamos olhar a memória através do "[...] homem ordinário. Herói comum. Personagem disseminada. Caminhante inumerável. Invocando, [...] o ausente que lhes dá princípio e necessidade [...] A este oráculo que se confunde com o rumor da história [...]" (CERTEAU, 1994, p.57).

No sujeito simples, ordinário, no dizer de Certeau, se dá também, e principalmente, a manifestação de identidade e nacionalidade, pois sob a ótica do autor, "Os projetores abandonaram os atores donos de nomes próprios e de brasões sociais para voltar-se para o coro dos figurantes amontoados dos lados, e depois fixar-se enfim na multidão do público" (CERTEAU, 1994, p.57).

Mais do que nunca urge que se atente ao processo de desenvolvimento social, onde a globalização, e por que não dizer a "massificação" das sociedades contemporâneas, interferem no fazer cotidiano, com novos valores e significados, novas práticas e novas formas de sociabilidade, intervindo na construção e legitimação da memória social representada pelo patrimônio cultural.

Qualquer política cultural sobre os bens patrimoniais não pode deixar de tomar as práticas sociais, suas representações e interpretações como força motriz para o assentamento de um patrimônio pautado numa memória que possibilite um sentimento de pertencimento no que se refere ao seu ambiente social. Um patrimônio cultural pensado e considerado nos usos sociais, nas apropriações que a sociedade faz da sua memória, da sua história. Precisamos desses patrimônios que são memórias e dessas memórias que são patrimônios para que possamos utilizá-los como fontes informacionais para a pesquisa e adotá-las como uma forma de 
fortalecer o processo de ensino como um espaço de construção e exercício da cidadania.

Partindo dessa problemática precisamos analisar o caráter educacional do patrimônio cultural do espaço urbano através dos trabalhos realizados nas escolas e na comunidade; identificar se o que é instituído objetivamente como patrimônio cultural é reconhecido e legitimado pela comunidade como histórico e coletivo, isto é, faça parte da sua memória social; verificar até que ponto o que existe de memória social pode se constituir como bem patrimonial; e identificar quais os fatores históricos, sociais, políticos e culturais que possam levar a comunidade a pensar - enquanto memória coletiva - um bem patrimonial.

\section{RE F E R Ê N C I A S}

BARTHES, R. A Aventura semiológica. Lisboa: Edições 70, 1987. p.189.

BRASIL. Constituição da República Federativa do Brasil. 1988.

BRASIL. Decreto-lei no 25/37, Organiza a proteção do patrimônio histórico e artístico nacional. [s.I.: s.n], 1937.

CANCLINI, N.G. O Patrimônio cultural e a construção imaginária do nacional. Revista do Patrimônio Histórico e Artístico Nacional, n. 23, p.95-96, 1994.

CERTEAU, M. A Invenção do cotidiano: artes de fazer. Petrópolis: Vozes, 1994. p.13.
Acreditamos que refletir sobre estas questões se mostre oportuno, haja visto o impulso e a importância que o estudo da memória social vem apresentando atualmente. Há também, no nosso entender, um dado considerado novo que é importante realçar: a possibilidade de ver no patrimônio cultural, enquanto memória coletiva, uma valiosa fonte de informação para a pesquisa e para o ensino, capaz de promover a construção de um indivíduo atento ao processo de formação social. Implica, portanto, em encontrar um papel social e educacional para o patrimônio que venha a contribuir para que tenhamos cidadãos mais conscientes dos seus valores e, dessa forma, preservadores e construtores do seu espaço de vivência cotidiana.

CHARTIER, R. A História cultural: entre práticas e representações. Lisboa: Difel, 1990. p.16-19.

GEERTZ, C. A Interpretação das culturas. Rio de Janeiro: Zahar, 1978. p.15.

ORIÁ, R. Memória e ensino de história. In: ALMEIDA, A.M. (Org.). O Saber histórico na sala de aula. São Paulo: Contexto, 1997. p.131.

ROSSI, A. A Arquitetura da cidade. São Paulo: Martins Fontes, 1995. p.281.

SILVA, M.A. História: o prazer em ensino e pesquisa. São Paulo: Brasiliense, 1995. p.24. 